\title{
Vapor Deposition Techniques for Synthesis of Two-Dimensional Transition Metal Dichalcogenides
}

\author{
Jeong-Gyu Song, Kyunam Park, Jusang Park, Hyungjun Kim* \\ School of Electrical and Electronic Engineering, Yonsei University, Seoul 03722, Korea
}

*Correspondence to:

Kim H,

Tel: $+82-2-2123-5773$

Fax: +82-2-313-2879

E-mail: hyungjun@yonsei.ac.kr

Received September 11, 2015

Revised September 13, 2015

Accepted September 13, 2015
Two-dimensional (2D) transition metal dichalcogenides (TMDCs) have attracted significant attention due to their unique and exotic properties attributed to their low dimensionality. In particular, semiconducting 2D TMDCs such as $\mathrm{MoS}_{2}, \mathrm{WS}_{2}, \mathrm{MoSe}_{2}$, and $\mathrm{WSe}_{2}$ have been demonstrated to be feasible for various advanced electronic and optical applications. In these regards, process to synthesize high quality 2D TMDCs layers with high reliability, wafer-scale uniformity, controllable layer number and excellent electronic properties is essential in order to use 2D TMDCs in practical applications. Vapor deposition techniques, such as physical vapor deposition, chemical vapor deposition and atomic layer deposition, could be promising processes to produce high quality $2 \mathrm{D}$ TMDCs due to high purity, thickness controllability and thickness uniformity. In this article, we briefly review recent research trend on vapor deposition techniques to synthesize $2 \mathrm{D}$ TMDCs.

Key Words: Molybdenum disulfide, Transition metal dichalcogenides, Two-dimensional materials, Chemical vapor deposition, Atomic layer deposition

\section{INTRODUCTION}

Transition metal dichalcogenides (TMDCs) are layered materials with strong in-plane covalent bonding and weak out-of-plane van der Waals bonding which is similar with graphene (Novoselov et al., 2005; Ramakrishna Matte et al., 2010). In particular, semiconducting two-dimensional (2D) TMDCs ( $\mathrm{MX}_{2}: \mathrm{M}=\mathrm{Mo}, \mathrm{W}$ and etc., $\left.\mathrm{X}=\mathrm{S}, \mathrm{Se}, \mathrm{Te}\right)$, exfoliated from bulk TMDCs, exhibit not only good chemical stability and flexibility but also unique electronic and optical properties, including indirect-to-direct band gap transition depending on layer number, high carrier mobility (approximately $100 \mathrm{~cm}^{2} / \mathrm{Vs}$ ) and strong spin-orbit coupling due to their broken inversion symmetry (Mak et al., 2010; Radisavljevic et al., 2011; Wang et al., 2012; Chhowalla et al., 2013; Song et al., 2013). These peculiar properties of 2D TMDCs make it promising to be used in field-effect transistors (Radisavljevic et al., 2011; Baugher et al., 2013; Georgiou et al., 2013; Lee et al., 2013), sensors (He et al., 2012; Li et al., 2012; Late et al., 2013; Liu et al., 2014a), photodetectors (Zhang et al., 2012; Lopez-Sanchez et al., 2013; Song et al., 2015), piezoelectric (Wu et al., 2014), and solar cell (Bernardi et al., 2013; Cheng et al., 2014; Furchi et al., 2014; Lee et al., 2014a) for future applications in such as wearable and flexible electronic devices which require compact, lightweight and high electrical and optical performance (Wang et al., 2012; Song et al., 2015).

One of the most important research field in 2D TMDCs is the reliable synthesis of 2D TMDCs with large area uniformity and layer number controllability. To date, the mechanical and chemical exfoliation methods have been employed to produce 2D TMDCs (Coleman et al., 2011; Eda et al., 2011;

This work was supported by the National Research Foundation of Korea (NRF) grant funded by the Korea government (MSIP) (No. NRF-2014R1A2A1A11052588), the Center for Integrated Smart Sensors funded by the Ministry of Science, ICT \& Future Planning as Global Frontier Project (CISS-2011-0031848), Samsung Display Co., Ltd., and Korea Evaluation Institute of Industrial Technology (KEIT) funded by the Ministry of Trade, Industry and Energy (MOTIE) (Project No. 10050296, Large scale (Over 8“) synthesis and evaluation technology of 2D chalcogenides for next generation electronic devices).

(a) This is an open-access article distributed under the terms of the Creative Commons Attribution Non-Commercial License (http://creativecommons.org/licenses/by-nc/4.0) which permits unrestricted noncommercial use, distribution, and reproduction in any medium, provided the original work is properly cited.

Copyrights (c) 2015 by Korean Society of Microscopy 
Radisavljevic et al., 2011; Li et al., 2012; Nicolosi et al., 2013). The exfoliated 2D TMDCs are suitable for basic research and demonstration of concept application since they have high crystallinity and inherent properties. However, the exfoliated 2D TMDCs have shown several limitations such as isolation, small size (usually less than a few $\mu \mathrm{m}$ ), and low productivity, which make it difficult to be used 2D TMDCs in practical devices. Thus, significant efforts have been devoted to synthesize high quality and large area 2D TMDCs. Recently several studies have shown synthesis of 2D TMDCs using various methods based on the vapor deposition techniques: sulfurization of metal and metal oxide thin films (Lin et al., 2012; Zhan et al., 2012; Elías et al., 2013; Liu et al., 2014b), chemical vapor deposition (CVD) (Lee et al., 2012; Huang et al., 2013; Najmaei et al., 2013; van der Zande et al., 2013; Cong et al., 2014; Ji et al., 2014; Ling et al., 2014; Shaw et al., 2014; Dumcenco et al., 2015; Kang et al., 2015) and atomic layer deposition (ALD) (Song et al., 2013; Jin et al., 2014; Tan et al., 2014; Song et al., 2015). In this review, synthetic methods for 2D TMDCs, mainly focused on the $\mathrm{MoS}_{2}$ and $\mathrm{WS}_{2}$ which are the most studied 2D TMDCs, will be presented.

\section{CHALCOGENIZATION OF METAL AND METAL OXIDE THIN FILM}

Initial studies on the synthesis of $2 \mathrm{D} \mathrm{MoS}_{2}$ were focused on the sulfurization of $\mathrm{Mo}$ and $\mathrm{MoO}_{\mathrm{x}}$ thin films, which were deposited by physical vapor deposition (PVD) at high temperature. Zhan et al. (2012) reported that the synthesis of $\mathrm{MoS}_{2}$ film by thermal annealing (at $750^{\circ} \mathrm{C}$ ) of PVD Mo thin film on $\mathrm{SiO}_{2} / \mathrm{Si}$ substrate in sulfur vapor as shown in Fig. 1A-D. Similarly, Lin et al. (2012) reported waferscale (2 inch) $\mathrm{MoS}_{2}$ thin layers synthesis by sulfurization of $\mathrm{MoO}_{3}$ thin film at $1,000^{\circ} \mathrm{C}$ (Fig. $1 \mathrm{E}-\mathrm{G}$ ). Although these

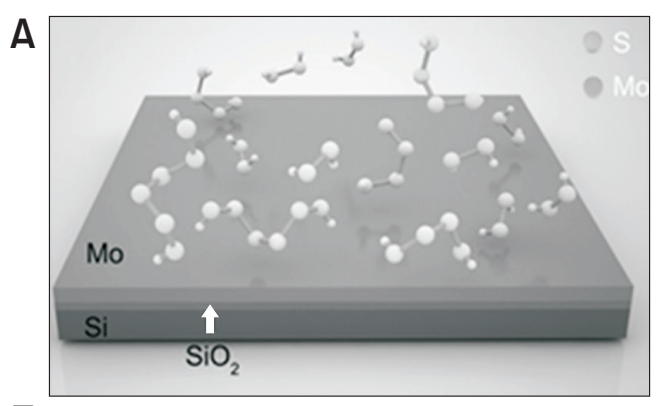

E

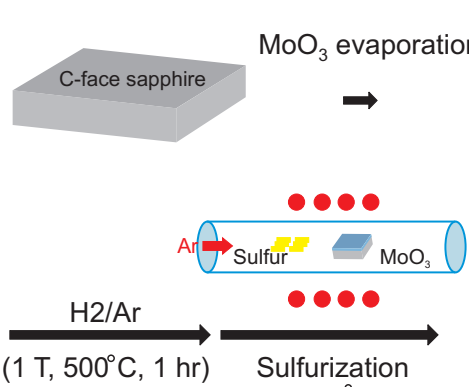

$\left(600 \mathrm{~T}, 1,000^{\circ} \mathrm{C}, 30 \mathrm{~min}\right)$
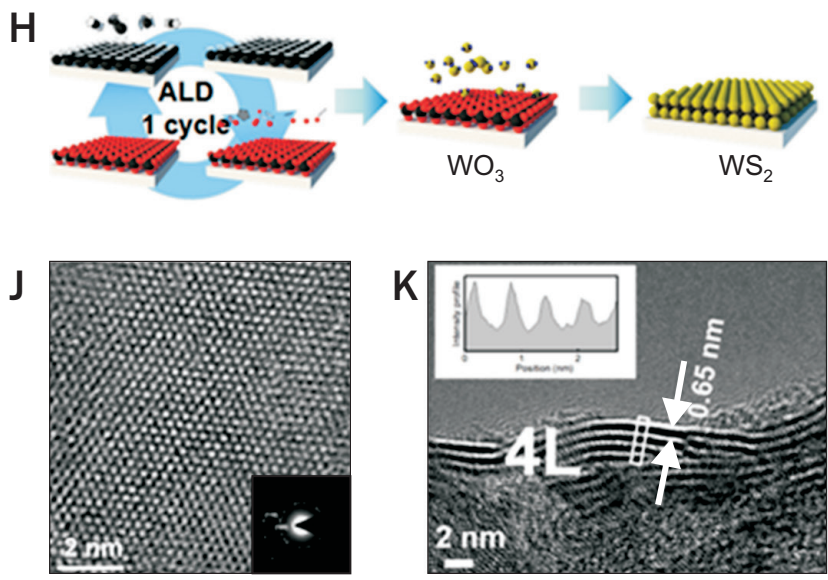
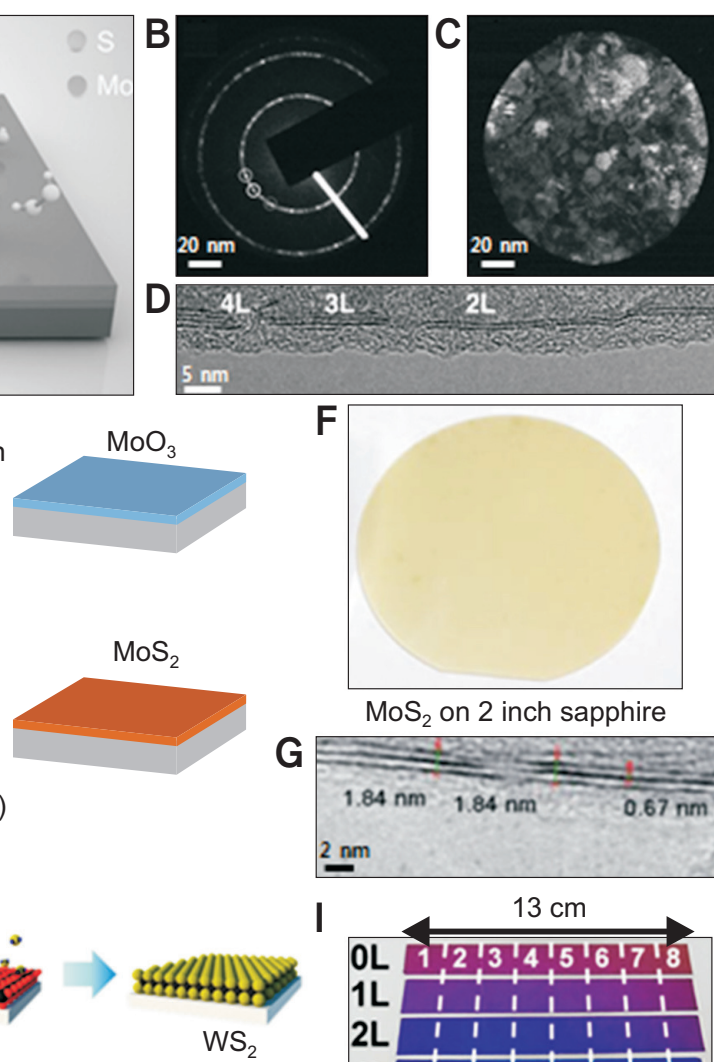

\section{G}

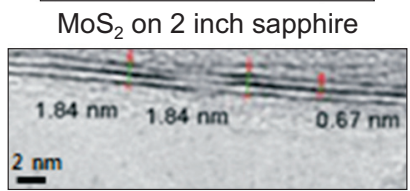

I
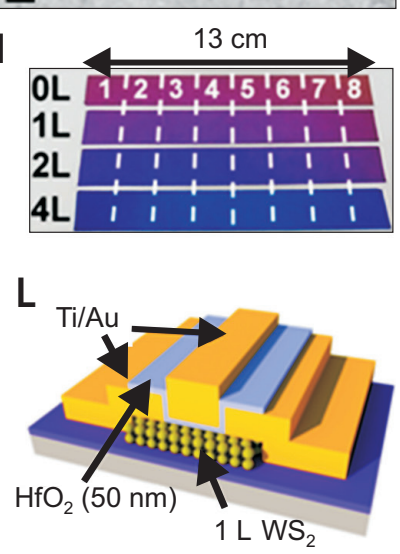

Fig. 1. (A) Schematic illustration of Mo sulfurization. (B) Diffraction pattern taken from $\mathrm{MoS}_{2}$. (C) Dark field transmission electron microscopy (TEM) image of $\mathrm{MoS}_{2}$. (D) Cross-sectional high-resolution TEM (HRTEM) image of $\mathrm{MoS}_{2}$. (E) Synthesis procedure of $\mathrm{MoO}_{3}$ sulfurization. (F) $\mathrm{MoS}_{2}$ on a 2 inch sapphire wafer. (G) Cross-sectional HRTEM image of $\mathrm{MoS}_{2}$. (H) Synthesis procedure for the atomic layer deposition (ALD) $\mathrm{WO}_{3}$ sulfurization. (I) Large-area (approximately $13 \mathrm{~cm}$ ) mono-, bi-, and tetralayer $\mathrm{WS}_{2}$ on $\mathrm{SiO}_{2}$ substrates. (J) A HRTEM image of a monolayer $\mathrm{WS}_{2}$, and the diffraction pattern of $\mathrm{WS}_{2}$ (inset). (K) Cross-sectional HRTEM image of tetralayer $\mathrm{WS}_{2}$. (L) Field effect transistor structure based on $\mathrm{WS}_{2}$. Fig. 1A-D reproduced from the article of Zhan et al. (2012) (Small 8, 966-971) with original copyright holder's permission. Fig. 1E-G reproduced from the article of Lin et al. (2012) (Nanoscale 4, 6637-6641) with original copyright holder's permission. Fig. $1 \mathrm{H}-\mathrm{L}$ reproduced from the article of Song et al. (2013) (ACS Nano 7, 1133311340 ) with original copyright holder's permission. 
sulfurization methods are simple and easy to produce 2D $\mathrm{MoS}_{2}$, several limitations exist such as difficulty in precise thickness control and in wafer-scale thickness uniformity of PVD Mo and $\mathrm{MoO}_{\mathrm{x}}$. Thus, precise control on the thickness of metal oxide film is essential to obtain layer number controlled, wafer-scale uniform 2D TMDCs. Recently, Song et al. (2013) demonstrated the synthesis of high quality $\mathrm{WS}_{2}$ by the sulfurization of $\mathrm{WO}_{3}$ thin film deposited by ALD. Since ALD has inherently excellent ability to control the film thickness over wafer scale, the synthesized $\mathrm{WS}_{2}$ layer has retains the inherent benefits of the ALD process as well as high mobility of approximately $4 \mathrm{~cm}^{2} / \mathrm{Vs}$ (Fig. $1 \mathrm{H}-\mathrm{L}$ ). Further, latest report by Song et al. (2015) has shown that the composition controllable synthesis of $\mathrm{Mo}_{1-\mathrm{x}} \mathrm{W}_{\mathrm{x}} \mathrm{S}_{2}$ alloy using sulfurization of super-cycle $\mathrm{ALD} \mathrm{Mo}_{1-\mathrm{x}} \mathrm{W}_{\mathrm{x}} \mathrm{O}_{\mathrm{y}}$. Based on this, they synthesized a vertically composition-controlled $\mathrm{Mo}_{1-\mathrm{x}} \mathrm{W}_{\mathrm{x}} \mathrm{S}_{2}$ multilayer that has broadband light absorption. Since the various transition metal oxides can be easily deposited by ALD, sulfurization (or selenization) of ALD metal oxide could be extended to synthesis of various 2D TMDCs.

\section{CHEMICAL VAPOR DEPOSITION}

The synthesis of 2D TMDCs using CVD with metal oxide

\section{A}

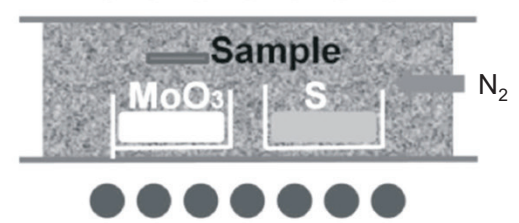

D

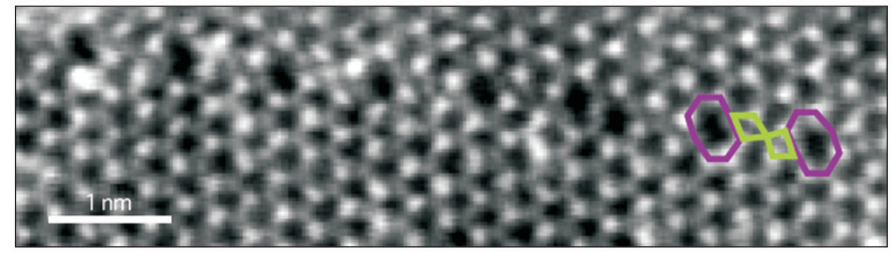

G
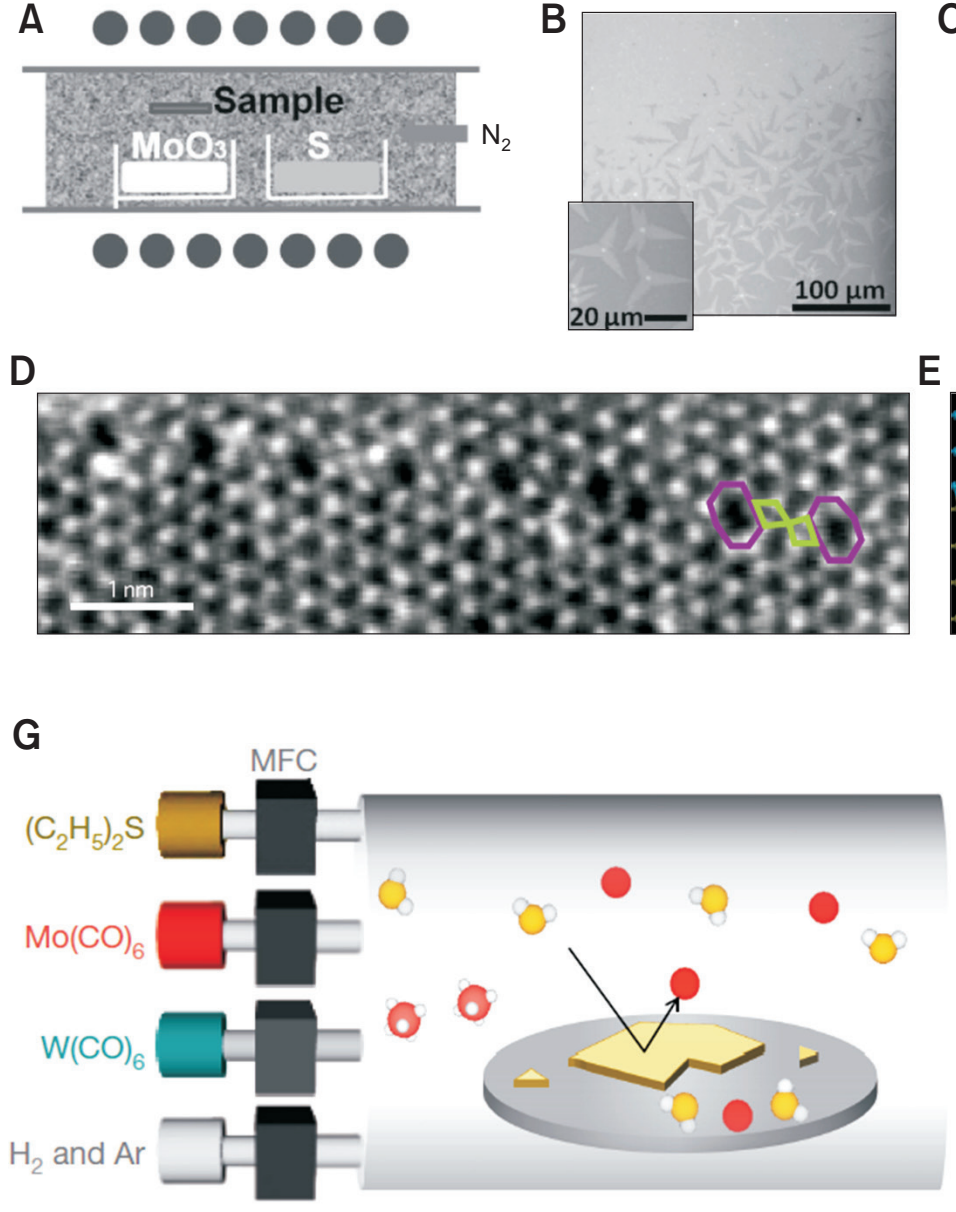

E
C
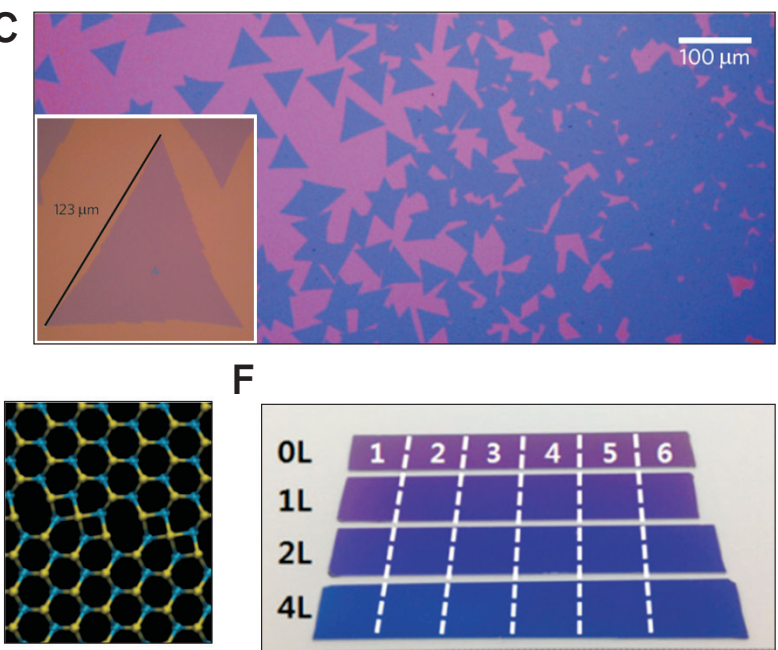

$\mathbf{F}$

$\mathrm{H}$

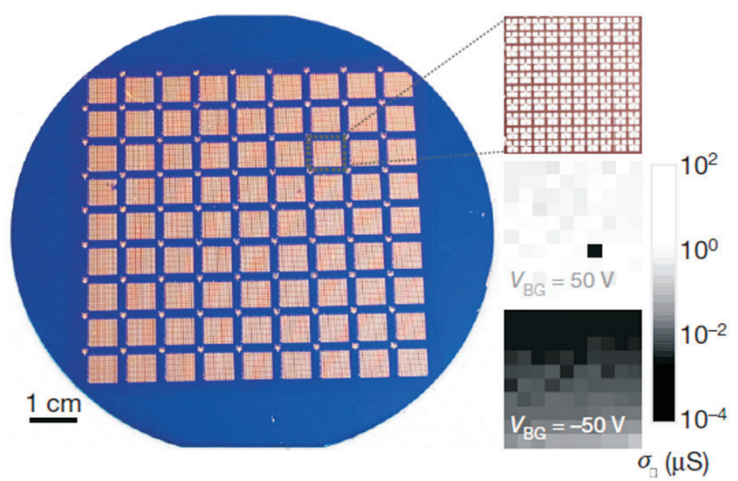

Fig. 2. (A) Schematic illustration of chemical vapor deposition (CVD) $\mathrm{MoS}_{2}$. (B) The optical microscopy (OM) images of $\mathrm{CVD}^{\mathrm{M}} \mathrm{MoS}_{2}$ on the $\mathrm{SiO}_{2}$ substrate treated with reduce graphene oxide solution. (C) $\mathrm{OM}$ image of $\mathrm{CVD} \mathrm{MoS}$ on a $\mathrm{SiO}_{2}$ substrate, and $\mathrm{OM}$ image of a monolayer $\mathrm{CVD} \mathrm{MoS}_{2}$ triangle with size up to $120 \mu \mathrm{m}$ in lateral (inset). (D) High-resolution transmission electron microscopy image of the grain boundary of $\mathrm{CVD} \mathrm{MoS}_{2}$ with shown a periodic line of 8-4-4 ring defects. (E) An atomistic model of the experimental structure shown in Fig. 2D. (F) Large-area $\left(1 \times 7 \mathrm{~cm}^{2}\right)$ mono-, bi-, and tetralayered CVD $\mathrm{WS}_{2}$ on $\mathrm{SiO}_{2}$ substrates. (G) Schematic illustration of metal-organic CVD MoS${ }_{2}$ and $\mathrm{WS}_{2}$. (H) Batch-fabricated $8 \times 100 \mathrm{MoS}_{2}$ field effect transistor arrays on a 4 -inch $\mathrm{SiO}_{2}$ wafer. Top inset: enlarged image of one square containing 100 devices. Middle and bottom insets: corresponding color maps of $\sigma_{\square}$ at gate bias $\mathrm{V}_{\mathrm{BG}}=50 \mathrm{~V}$ and $-50 \mathrm{~V}$, respectively. Fig. 2A and B reproduced from the article of Lee et al. (2012) (Advanced Materials 24, 2320-2325) with original copyright holder's permission. Fig. 2C-E reproduced from the article of van der Zande et al. (2013) (Nature Materials 12, 554-561) with original copyright holder's permission. Fig. 2F reproduced from the article of Park et al. (2015) (Nanoscale 7, 1308-1313) with original copyright holder's permission. Fig. 2G and H reproduced from the article of Kang et al. (2015) (Nature 520, 656-660) with original copyright holder's permission. 
$\left(\mathrm{MO}_{3}, \mathrm{M}=\mathrm{Mo}\right.$ and $\left.\mathrm{W}\right)$ and chalcogen $(\mathrm{X}=\mathrm{S}$ and $\mathrm{Se})$ powders at $600^{\circ} \mathrm{C} \sim 700^{\circ} \mathrm{C}$ has been extensively studied (Lee et al., 2012; Najmaei et al., 2013; van der Zande et al., 2013; Ling et al., 2014). In this process scheme, $\mathrm{MO}_{3-\mathrm{x}}$ is formed by the reduction of $\mathrm{MO}_{3}$ vapor. Subsequently, $\mathrm{MO}_{3-\mathrm{x}}$ vapor diffuses to the substrate and reacts with $\mathrm{X}$ vapor. Lee et al. (2012) reported the promotion of $2 \mathrm{D} \mathrm{MoS}_{2}$ synthesis using substrate treatment by graphene like species, such as reduced graphene oxide, perylene-3,4,9,10-tetracarboxylic acidtetrapotassium salt and perylene-3,4,9,10-tetracarboxylicdianhydride. Here, the species used for surface treatment promote act as seeds for $2 \mathrm{D} \mathrm{MoS}_{2}$ formation and enhance the lateral growth of $\mathrm{MoS}_{2}$, as shown in Fig. 2A and B (Lee et al., 2012). Meanwhile, van der Zande et al. (2013) reported the synthesis of large $\mathrm{MoS}_{2}$ single crystal grains (at $700^{\circ} \mathrm{C}$ ) up to $120 \mu \mathrm{m}$ without seeding. In this report, they used ultraclean substrates and fresh precursors to promote grain size (Fig. 2C). Further, they have observed that formation of periodic line of 8-4-4 ring defects at grain boundary of CVD $\mathrm{MoS}_{2}$ as represented in Fig. 2D and E. Recent studies on the CVD with $\mathrm{MO}_{3}$ and $\mathrm{X}$ powder have been focused on the synthesis of $\mathrm{MoS}_{2}$ and $\mathrm{WS}_{2}$ on single crystal substrate for enhancing grain size. In particular, orientation aligned growth of CVD $\mathrm{MoS}_{2}$ on c-plane sapphire has been reported by Ji et al. (2014) and Dumcenco et al. (2015). They have shown that the same hexagonal lattice symmetry induces van der Waals epitaxy of $\mathrm{MoS}_{2}$ on c-plane sapphire, which suggests possibility of wafer-scale growth of single-crystal $\mathrm{MoS}_{2}$ similar with graphene on hydrogenterminated germanium (Lee et al., 2014b).

However, the CVD process based on $\mathrm{MO}_{3}$ and $\mathrm{X}$ powder is critically depending on process conditions such as amount of $\mathrm{MO}_{3}$ and $\mathrm{X}$ powder, non-homogeneous diffusion of vaporized molecules, and outgoing flow of vapors from the chamber. Since these process conditions cannot be easily controlled, uniform and high quality synthesis is hardly achievable (Najmaei et al., 2013; van der Zande et al., 2013;
A

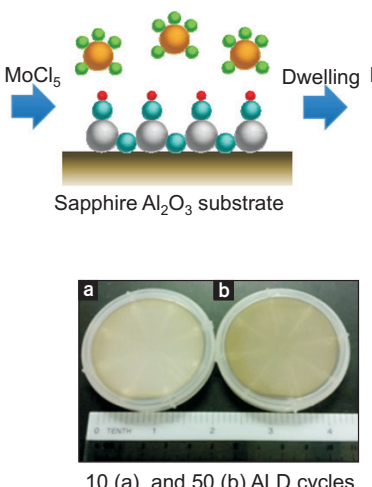

10 (a) and 50 (b) ALD cycles
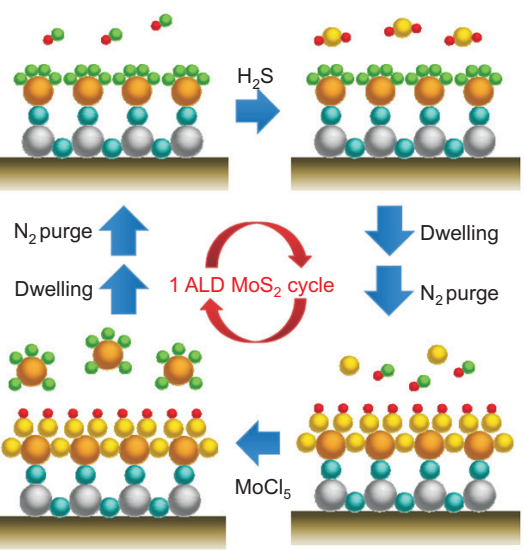

QAl $\odot \circ \cdot \mathrm{H} \bigcirc \mathrm{MO} \bullet \mathrm{Cl} \bigcirc \mathrm{s}$

C

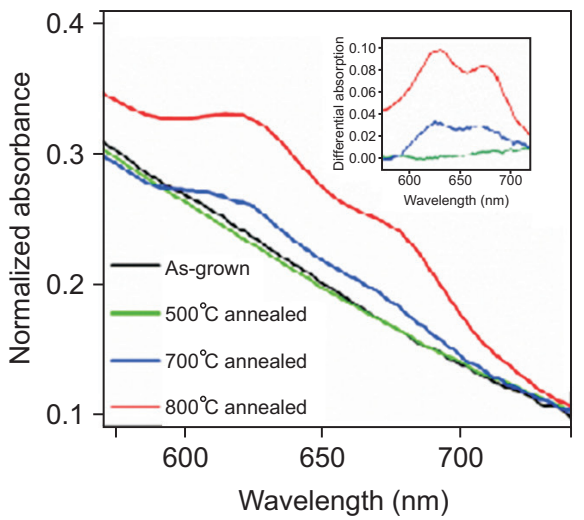

D

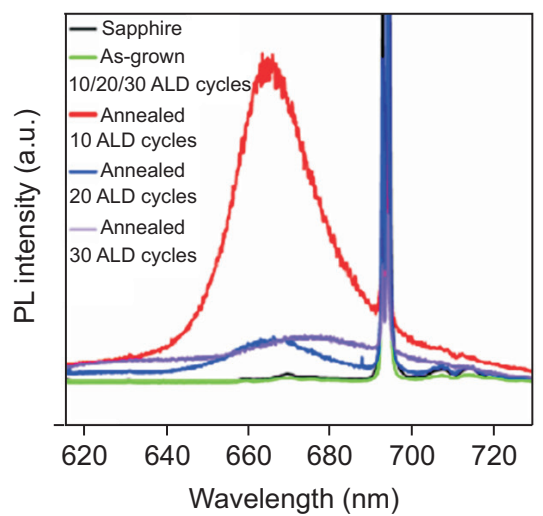

B

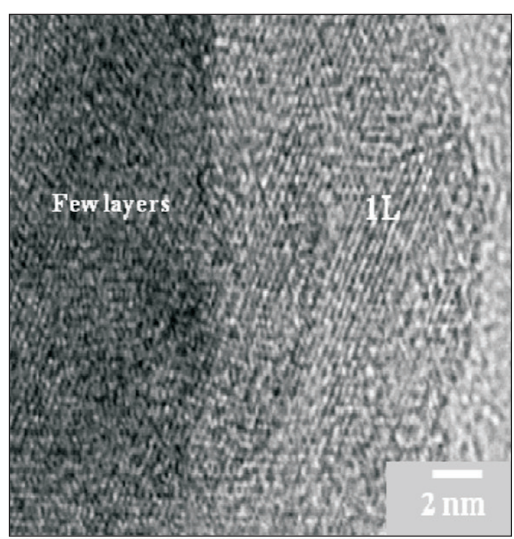

E

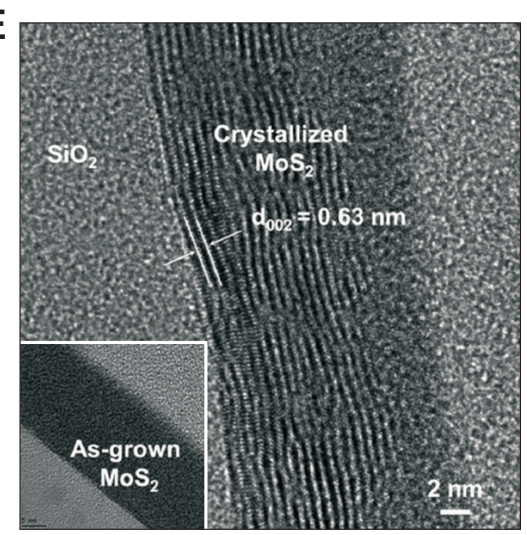

Fig. 3. (A) Schematic illustration of one growth cycle of atomic layer deposition (ALD) MoS 2 . (B) High-resolution transmission electron microscopy (HRTEM) image of mono- and multilayer ALD $\mathrm{MoS}_{2}$. (C) Optical absorption. (D) Photoluminescence spectra for ALD-deposited, as-grown or annealed MoS 2 . (E) Cross-sectional HRTEM image of the ALD $\mathrm{MoS}_{2}$ after annealed at $900^{\circ} \mathrm{C}$ for 5 minutes. Fig. 3A-D reproduced from the article of Tan et al. (2014) (Nanoscale 6, 10584-10588) with original copyright holder's permission. Fig. 3E reproduced from the article of Jin et al. (2014) (Nanoscale 6, 14453-14458) with original copyright holder's permission. 
Park et al., 2015). Thus, CVD of 2D TMDCs based on gas precursor and reactant is more promising. As shown in Fig. 2F, Park et al. (2015) reported layer number controllable and wafer-scale uniform growth of $\mathrm{WS}_{2}$ using $\mathrm{WCl}_{6}$ and $\mathrm{H}_{2} \mathrm{~S}$ at $700^{\circ} \mathrm{C}$. More recently, Kang et al. (2015) reported high quality $\mathrm{WS}_{2}$ synthesis based on metal-organic CVD (MOCVD) using $\mathrm{Mo}(\mathrm{CO})_{6}, \mathrm{~W}(\mathrm{CO})_{6}$, and $\left(\mathrm{C}_{2} \mathrm{H}_{5}\right)_{2} \mathrm{~S}$ at $550^{\circ} \mathrm{C}$ (Fig. 2G). The synthesized MOCVD 2D TMDCs exhibited homogeneous electrical properties with high electron mobility of $30 \mathrm{~cm}^{2}$ / Vs and $99 \%$ devices yield (Fig. $2 \mathrm{H}$ ). However, the growth rate was reported to be very low, which requires 26 hours to grow monolayer 2D TMDCs.

\section{ATOMIC LAYER DEPOSITION}

Due to benefits of ALD in terms of thickness controllability of thin film in nanometer scale, ALD is considered to be a promising candidate to synthesis technique for 2D TMDCs. In fact, various ALD processes of chalcogenides thin films such as $\mathrm{ZnS}, \mathrm{GaS}, \mathrm{CdS}$, etc, have been reported for photovoltaic and energy storage materials (Dasgupta et al., 2015). Recently, a few reports on ALD $\mathrm{MoS}_{2}$ are available as shown in Fig. 3. Tan et al. (2014) reported growth of ALD $\mathrm{MoS}_{2}$ film using $\mathrm{MoCl}_{5}$ and $\mathrm{H}_{2} \mathrm{~S}$ at $300^{\circ} \mathrm{C}$ (Fig. 3A-D). In addition, low temperature (at $\left.100^{\circ} \mathrm{C}\right) \mathrm{ALD} \mathrm{MoS}$ process using $\mathrm{Mo}(\mathrm{CO})_{6}$ and $\left(\mathrm{CH}_{3}\right)_{2} \mathrm{~S}_{2}$ is

Table 1. Summary of the vapor deposition techniques for synthesis of two-dimensional TMDCs

\begin{tabular}{|c|c|c|c|c|c|}
\hline TMDCs & Process & $\begin{array}{c}\text { Process temperature } \\
\left({ }^{\circ} \mathrm{C}\right)\end{array}$ & Layer number & $\begin{array}{l}\text { Electrical properties } \\
\left(\mathrm{cm}^{2} \mathrm{~V}^{-1} \mathrm{~s}^{-1}\right)\end{array}$ & Reference \\
\hline \multicolumn{6}{|c|}{ Chalcogenization of metal and metal oxide thin film } \\
\hline \multirow[t]{3}{*}{$\mathrm{MoS}_{2}$} & $\begin{array}{l}\text { Sulfurization (S powder) of PVD Mo } \\
(1 \sim 5 \mathrm{~nm})\end{array}$ & 750 & $\begin{array}{l}\text { Mono- and few-layer } \\
\text { mixing }\end{array}$ & $\begin{array}{l}\text { Back gate FET } \\
\text { Mobility: } 0.004 \text { to } 0.04\end{array}$ & Zhan et al. (2012) \\
\hline & Sulfurization (S powder) of $\mathrm{PVD} \mathrm{MoO}_{3}$ & 1,000 & $\mathrm{Bi}$ - and few-layer & $\begin{array}{l}\text { Back gate FET } \\
\text { Mobility: } 0.8\end{array}$ & Lin et al. (2012) \\
\hline & Sulfurization $\left(\mathrm{H}_{2} \mathrm{~S}\right)$ of $\mathrm{ALD} \mathrm{MoO}_{3}$ & $\begin{array}{l}\text { Annealing: 1st, } 600 \text {; } \\
\text { 2nd, } 1,000\end{array}$ & Mono-, bi-, and tri-layer & - & Song et al. (2015) \\
\hline \multirow[t]{2}{*}{$\mathrm{WS}_{2}$} & Sulfurization (S powder) of $\mathrm{PVD} \mathrm{WO}_{3}$ & 800 & Mono-, bi-, and tri-layer & - & Elías et al. (2013) \\
\hline & Sulfurization $\left(\mathrm{H}_{2} \mathrm{~S}\right)$ of $\mathrm{ALD} \mathrm{WO}_{3}$ & 1,000 & Mono-, bi-, and tetra-layer & $\begin{array}{l}\text { Top gate FET } \\
\text { Mobility: } 3.9\end{array}$ & Song et al. (2013) \\
\hline \multicolumn{6}{|c|}{ Chemical vapor deposition } \\
\hline \multirow[t]{5}{*}{$\mathrm{MoS}_{2}$} & $\mathrm{MoO}_{3}$ and S powder with seeding & 650 & Monolayer & $\begin{array}{l}\text { Back gate FET } \\
\text { Mobility: } 0.02\end{array}$ & $\begin{array}{l}\text { Lee et al. (2012); } \\
\text { Ling et al. (2014) }\end{array}$ \\
\hline & $\mathrm{MoO}_{3}$ and $\mathrm{S}$ powder & 700 & Monolayer & $\begin{array}{l}\text { Back gate FET } \\
\text { Mobility: } 3 \text { to } 4\end{array}$ & $\begin{array}{l}\text { van der Zande et al. } \\
\text { (2013) }\end{array}$ \\
\hline & $\mathrm{MoO}_{3}$ nanoribbons and $\mathrm{S}$ powder & 850 & Monolayer & $\begin{array}{l}\text { Back gate FET } \\
\text { Mobility: } 4.3\end{array}$ & Najmaei et al. (2013) \\
\hline & $\mathrm{MoO}_{3}$ and $\mathrm{S}$ powder & 850 & Monolayer on sapphire & $\begin{array}{l}\text { Back gate FET } \\
\text { Mobility: } 0.1 \text { to } 1\end{array}$ & Ji et al. (2014) \\
\hline & $\mathrm{MoO}_{3}$ and $\mathrm{S}$ powder & 700 & Monolayer on sapphire & $\begin{array}{l}\text { Back gate FET } \\
\text { Mobility: } 25\end{array}$ & $\begin{array}{l}\text { Dumcenco et al. } \\
\text { (2015) }\end{array}$ \\
\hline \multirow[t]{2}{*}{$\mathrm{WS}_{2}$} & $\mathrm{WO}_{3}$ and $\mathrm{S}$ powder & 750 & Monolayer & - & Cong et al. (2014) \\
\hline & $\mathrm{WCl}_{6}$ and $\mathrm{H}_{2} \mathrm{~S}$ gas & 700 & Mono-, bi-, and tetra-layer & - & Park et al. (2015) \\
\hline $\mathrm{MoS}_{2}, \mathrm{WS}_{2}$ & $\mathrm{Mo}(\mathrm{CO})_{6}, \mathrm{~W}(\mathrm{CO})_{6}$, and diethyl sulfide & 550 & Monolayer & $\begin{array}{l}\text { Top gate FET } \\
\text { Mobility: } 30\end{array}$ & Kang et al. (2015) \\
\hline $\mathrm{MoSe}_{2}$ & $\mathrm{MoO}_{3}$ and Se powder & 750 & Mono- and few-layer & - & Shaw et al. (2014) \\
\hline $\mathrm{WSe}_{2}$ & $\mathrm{WO}_{3}$ and Se powder & 750 & Monolayer & $\begin{array}{l}\text { Electric double-layer FET } \\
\text { Mobility: } 90\end{array}$ & Huang et al. (2013) \\
\hline \multicolumn{6}{|c|}{ Atomic layer deposition } \\
\hline \multirow[t]{2}{*}{$\mathrm{MoS}_{2}$} & $\mathrm{Mo}(\mathrm{CO})_{6}$ and dimethyl disulfide & 100 & Amorphous & - & Jin et al. (2014) \\
\hline & $\mathrm{MoCl}_{5}$ and $\mathrm{H}_{2} \mathrm{~S}$ gas & 300 & Amorphous & - & Tan et al. (2014) \\
\hline
\end{tabular}

TMDCs, transition metal dichalcogenides; PVD, physical vapor deposition; FET, field effect transistor; ALD, atomic layer deposition. 
reported by Jin et al. (2014). However, the reported ALD MoS films show low optical property attributed to amorphous phase as shown in Fig. 3E, which limits there use for the electrical and optical applications. The basic problem of ALD processes for TMDCs are the difficulty in the formation of layered structure. The deposition of high quality TMDCs by direct ALD process is yet to come.

\section{CONCLUSIONS}

This review provides a brief collection of literatures on the synthesis of 2D TMDCs materials as summarized in Table 1. Vapor deposition techniques, which are suitable for waferscale and high-quality synthesis of 2D TMDCs such as $\mathrm{MoS}_{2}$,
$\mathrm{WS}_{2}, \mathrm{WSe}_{2}$ and $\mathrm{MoSe}_{2}$ for electronic and optoelectronic devices have been developed. To realize the advanced applications using 2D TMDCs, more efforts are needed to resolve many issues related to the growth, including high reliability, layer number controllability, wafer-scale uniformity and high crystallinity. Furthermore, synthesis of high quality 2D TMDCs will boost the study on the stacking of different types of 2D materials which could exhibit novel properties and new phenomena.

\section{CONFLICT OF INTEREST}

No potential conflict of interest relevant to this article was reported.

\section{REFERENCES}

Baugher B W H, Churchill H O H, Yang Y, and Jarillo-Herrero P (2013) Intrinsic electronic transport properties of high-quality monolayer and bilayer MoS2. Nano Letters 13, 4212-4216.

Bernardi M, Palummo M, and Grossman J C (2013) Extraordinary sunlight absorption and $1 \mathrm{~nm}$-thick photovoltaics using two-dimensional monolayer materials. Nano Letters 13, 3664-3670.

Cheng R, Li D, Zhou H, Wang C, Yin A, Jiang S, Liu Y, Chen Y, Huang Y, and Duan $X$ (2014) Electroluminescence and photocurrent generation from atomically sharp WSe2/MoS2 heterojunction pn diodes. Nano Letters 14, 5590-5597.

Chhowalla M, Shin H S, Eda G, Li L J, Loh K P, and Zhang H (2013) The chemistry of two-dimensional layered transition metal dichalcogenide nanosheets. Nature Chemistry 5, 263-275.

Coleman J N, Lotya M, O'Neill A, Bergin S D, King P J, Khan U, Young K, Gaucher A, De S, and Smith R J (2011) Two-dimensional nanosheets produced by liquid exfoliation of layered materials. Science 331, 568571.

Cong C, Shang J, Wu X, Cao B, Peimyoo N, Qiu C, Sun L, and Yu T (2014) Synthesis and optical properties of large-area single-crystalline $2 \mathrm{D}$ semiconductor WS2 monolayer from chemical vapor deposition. Advanced Optical Materials 2, 131-136.

Dasgupta N P, Meng X, Elam J W, and Martinson A B (2015) Atomic layer deposition of metal sulfide materials. Accounts of Chemical Research 48, 341-348.

Dumcenco D, Ovchinnikov D, Marinov K, Lazic P, Gibertini M, Marzari N, Sanchez O L, Kung Y C, Krasnozhon D, and Chen M W (2015) Largearea epitaxial monolayer MoS2. ACS Nano 9, 4611-4620.

Eda G, Yamaguchi H, Voiry D, Fujita T, Chen M, and Chhowalla M (2011) Photoluminescence from chemically exfoliated MoS2. Nano Letters 11, 5111-5116.

Elías A L, Perea-López N, Castro-Beltrán A, Berkdemir A, Lv R, Feng S, Long A D, Hayashi T, Kim Y A, Endo M, Gutiérrez H R, Pradhan N R, Balicas L, Mallouk T E, López-Urías F, Terrones H, and Terrones M (2013) Controlled synthesis and transfer of large-area WS2 sheets: from single layer to few layers. ACS Nano 7, 5235-5242.

Furchi M M, Pospischil A, Libisch F, Burgdörfer J, and Mueller T (2014)
Photovoltaic effect in an electrically tunable van der Waals heterojunction. Nano Letters 14, 4785-4791.

Georgiou T, Jalil R, Belle B D, Britnell L, Gorbachev R V, Morozov S V, Kim Y J, Gholinia A, Haigh S J, and Makarovsky O (2013) Vertical fieldeffect transistor based on graphene-WS2 heterostructures for flexible and transparent electronics. Nature Nanotechnology 8, 100-103.

He Q, Zeng Z, Yin Z, Li H, Wu S, Huang X, and Zhang H (2012) Fabrication of flexible MoS2 thin-film transistor arrays for practical gas-sensing applications. Small 8, 2994-2999.

Huang J K, Pu J, Hsu C L, Chiu M H, Juang Z Y, Chang Y H, Chang W H, Iwasa Y, Takenobu T, and Li L J (2013) Large-area synthesis of highly crystalline WSe2 monolayers and device applications. ACS Nano $\mathbf{8}$, 923-930.

Ji Q, Kan M, Zhang Y, Guo Y, Ma D, Shi J, Sun Q, Chen Q, Zhang Y, and Liu Z (2014) Unravelling orientation distribution and merging behavior of monolayer MoS2 domains on sapphire. Nano Letters 15, 198-205.

Jin Z, Shin S, Kwon D H, Han S J, and Min Y S (2014) Novel chemical route for atomic layer deposition of MoS2 thin film on SiO2/Si substrate. Nanoscale 6, 14453-14458.

Kang K, Xie S, Huang L, Han Y, Huang P Y, Mak K F, Kim C J, Muller D, and Park J (2015) High-mobility three-atom-thick semiconducting films with wafer-scale homogeneity. Nature 520, 656-660.

Late D J, Huang Y K, Liu B, Acharya J, Shirodkar S N, Luo J, Yan A, Charles D, Waghmare U V, Dravid V P, and Rao C N R (2013) Sensing behavior of atomically thin-layered MoS2 transistors. ACS Nano $\mathbf{7}$, 4879-4891.

Lee C H, Lee G H, van der Zande A M, Chen W, Li Y, Han M, Cui X, Arefe G, Nuckolls C, Heinz T F, Guo J, Hone J, and Kim P (2014a) Atomically thin p-n junctions with van der Waals heterointerfaces. Nat Nano $\mathbf{9}$, 676-681.

Lee G H, Yu Y J, Cui X, Petrone N, Lee C H, Choi M S, Lee D Y, Lee C, Yoo W J, and Watanabe K (2013) Flexible and transparent MoS2 field-effect transistors on hexagonal boron nitride-graphene heterostructures. ACS Nano 7, 7931-7936.

Lee J H, Lee E K, Joo W J, Jang Y, Kim B S, Lim J Y, Choi S H, Ahn S J, Ahn J R, and Park M H (2014b) Wafer-scale growth of single-crystal monolayer 
graphene on reusable hydrogen-terminated germanium. Science 344, 286-289.

Lee Y H, Zhang X Q, Zhang W, Chang M T, Lin C T, Chang K D, Yu Y C, Wang J T W, Chang C S, Li L J, and Lin T W (2012) Synthesis of largearea MoS2 atomic layers with chemical vapor deposition. Advanced Materials 24, 2320-2325.

Li H, Yin Z, He Q, Li H, Huang X, Lu G, Fam D W H, Tok A I Y, Zhang Q, and Zhang $H$ (2012) Fabrication of single- and multilayer MoS2 filmbased field-effect transistors for sensing $\mathrm{NO}$ at room temperature. Small 8, 63-67.

Lin Y C, Zhang W, Huang J K, Liu K K, Lee Y H, Liang C T, Chu C W, and Li L J (2012) Wafer-scale MoS2 thin layers prepared by MoO3 sulfurization. Nanoscale 4, 6637-6641.

Ling X, Lee Y H, Lin Y, Fang W, Yu L, Dresselhaus M S, and Kong J (2014) Role of the seeding promoter in MoS2 growth by chemical vapor deposition. Nano Letters 14, 464-472.

Liu B, Chen L, Liu G, Abbas A N, Fathi M, and Zhou C (2014a) Highperformance chemical sensing using schottky-contacted chemical vapor deposition grown monolayer MoS2 transistors. ACS Nano 5, 5304-5314.

Liu H, Antwi K K A, Chua S, and Chi D (2014b) Vapor-phase growth and characterization of Mo1-xWxS2 $(0 \leq x \leq 1)$ atomic layers on 2-inch sapphire substrates. Nanoscale 6, 624-629.

Lopez-Sanchez O, Lembke D, Kayci M, Radenovic A, and Kis A (2013) Ultrasensitive photodetectors based on monolayer MoS2. Nature Nanotechnology 8, 497-501.

Mak K F, Lee C, Hone J, Shan J, and Heinz T F (2010) Atomically thin MoS_ \{2\}: a new direct-gap semiconductor. Physical Review Letters 105, 136805.

Najmaei S, Liu Z, Zhou W, Zou X, Shi G, Lei S, Yakobson B I, Idrobo J C, Ajayan P M, and Lou J (2013) Vapour phase growth and grain boundary structure of molybdenum disulphide atomic layers. Nature Materials 12, 754-759.

Nicolosi V, Chhowalla M, Kanatzidis M G, Strano M S, and Coleman J N (2013) Liquid exfoliation of layered materials. Science $\mathbf{3 4 0 ,}$ 1226419.

Novoselov K, Jiang D, Schedin F, Booth T, Khotkevich V, Morozov S, and Geim A (2005) Two-dimensional atomic crystals. Proceedings of the National Academy of Sciences of the United States of America 102, 10451-10453.
Park J, Lee W, Choi T, Hwang S H, Myoung J M, Jung J H, Kim S H, and Kim H (2015) Layer-modulated synthesis of uniform tungsten disulfide nanosheet using gas-phase precursors. Nanoscale 7, 13081313.

Radisavljevic B, Radenovic A, Brivio J, Giacometti V, and Kis A (2011) Single-layer MoS2 transistors. Nature Nanotechnology 6, 147-150.

Ramakrishna Matte H S S, Gomathi A, Manna A K, Late D J, Datta R, Pati S K, and Rao C N R (2010) MoS2 and WS2 analogues of graphene. Angewandte Chemie 122, 4153-4156.

Shaw J C, Zhou H, Chen Y, Weiss N O, Liu Y, Huang Y, and Duan X (2014) Chemical vapor deposition growth of monolayer MoSe2 nanosheets. Nano Research 7, 511-517.

Song J G, Park J, Lee W, Choi T, Jung H, Lee C W, Hwang S H, Myoung J M, Jung J H, and Kim S H (2013) Layer-controlled, wafer-scale, and conformal synthesis of tungsten disulfide nanosheets using atomic layer deposition. ACS Nano 7, 11333-11340.

Song J G, Ryu G H, Lee S J, Sim S, Lee C W, Choi T, Jung H, Kim Y, Lee Z, Myoung J M, Dussarrat C, Lansalot-Matras C, Park J, Choi H, and Kim H (2015) Controllable synthesis of molybdenum tungsten disulfide alloy for vertically composition-controlled multilayer. Nat Commun $\mathbf{6}$, 7817.

Tan L K, Liu B, Teng J H, Guo S, Low H Y, and Loh K P (2014) Atomic layer deposition of a MoS2 film. Nanoscale 6, 10584-10588.

van der Zande A M, Huang P Y, Chenet D A, Berkelbach T C, You Y, Lee G H, Heinz T F, Reichman D R, Muller D A, and Hone J C (2013) Grains and grain boundaries in highly crystalline monolayer molybdenum disulphide. Nature Materials 12, 554-561.

Wang Q H, Kalantar-Zadeh K, Kis A, Coleman J N, and Strano M S (2012) Electronics and optoelectronics of two-dimensional transition metal dichalcogenides. Nature Nanotechnology 7, 699-712.

Wu W, Wang L, Li Y, Zhang F, Lin L, Niu S, Chenet D, Zhang X, Hao Y, and Heinz T F (2014) Piezoelectricity of single-atomic-layer MoS2 for energy conversion and piezotronics. Nature 514, 470-474.

Zhan Y, Liu Z, Najmaei S, Ajayan P M, and Lou J (2012) Large-area vaporphase growth and characterization of MoS2 atomic layers on a SiO2 substrate. Small 8, 966-971.

Zhang C, Wang S, Yang L, Liu Y, Xu T, Ning Z, Zak A, Zhang Z, Tenne R, and Chen $Q$ (2012) High-performance photodetectors for visible and near-infrared lights based on individual WS2 nanotubes. Applied Physics Letters 100, 243101. 